\title{
Study on the Spacecraft AIT Project Argument and Its Risk Management
}

\author{
Liu Yang ${ }^{1, a}$, Shan Weiwei ${ }^{2, b}$ \\ ${ }^{1}$ China Academy of Space Technology, No.104, Youyi Road, Haidian District, BeiJing, China \\ alyowenly@163.com, bsww_xjtu@163.com
}

Keywords: Spacecraft; AIT; Project argument; Risk management.

\begin{abstract}
This paper analyses and studies spacecraft AIT project argument, and puts forward argument methods and procedures suitable to spacecraft AIT according to the current status of argument and management modes in spacecraft development. At the same time, the risk management theory of NASA is introduced, analyzed as well as related theories are applied to the study of risks existing both in project argument of spacecraft AIT and throughout the argument process. After analyzing the risk management process with a specified risk as an example, we here propose the argument risk control method to decrease risks in argument of spacecraft AIT projects, to improve argument quality and to prepare a solid base for smooth implementation and completion of spacecraft development projects in future.
\end{abstract}

\section{Introduction}

In recent years, with spacecraft development tasks being rapidly increased and management modes of spacecraft development changing incessantly, AIT (Assembly Integration and Test), an important sub-system of spacecraft development program, has gradually launched the independent argument, which posed a challenge to the traditional management mode[1-3]. In proceedings of the argument, had such potential risks as in technology and finance been not recognized and eliminated, the development of spacecraft AIT would be affected to the extent of lacking development fund, delaying the development proceeding and even impeding the completion of the whole project[4,5]. While other countries have started risk management of spacecraft projects a long time ago, China has no such study in light of argument and risk management and control of spacecraft projects[6,7]. This paper, based on current related theories, proposes the method of argument of spacecraft AIT projects, researches and discusses the risk management in the proceedings of project argument, with an aim to lowering the probability and alleviating the harm caused by risks, to guaranteeing the full argument, to improving the argument quality and thus to preparing a sound base for the smooth completion of spacecraft projects.

\section{Introduction of Spacecraft AIT Projects argument}

Project argument. Project argument is a technical and economic research to analyze and assess the possibility in terms of technology, the profitability in terms of finance and the feasibility in terms of construction for a proposed project in a comprehensive and scientific manner. It serves as an important link and way to avoid and decrease wrong decisions on projects, improve returns and comprehensive efficiency of the investment. Project argument generally includes such following phases: initial stage; date collection and analysis; construction of all kinds of feasible technological solutions; project analysis and evaluation; formulate implementation program and project argument report.

Spacecraft AIT Projects argument. With high-tech, strict quality requirement and high risk, the spacecraft AIT project needs full analytic research and argument on related aspects such as feasibility as regards technology and finance as soon as being at the argument phase to guarantee the smooth development, launch and running on the due orbit of the spacecraft. So contrasting with traditional projects argument, the spacecraft development project argument requires higher requirements and a lower risk level. As an important part of spacecraft development, the AIT 
business shoulders tasks including assembling satellite and spaceship, professional test, environment experiment, launching site assembly and their management. The general assembly of spacecraft is the process that the spacecraft turns into the product. The environment experiment will make performance tests of spacecraft under mechanical, thermal and magnetic condition, as well as cooperate with related departments to undertake other kinds of tests. Spacecraft AIT project argument refers to the comprehensive technological and financial argument on whole AIT process argument including key technologies, supportive conditions and development of AIT at phases of establishment and feasibility study of spacecraft project. Firstly, on the basis of the top-level documents such as the overall design plan, staffs are responsible for the argument shall clarify the technological input of model AIT development, by which a primary AIT development plan or work program of the model is designed and a technological argument report is thus formulated, and a financial argument report is formed via analyzing the above technological argument report. The following figure shows all argument procedures of AIT development project establishment.

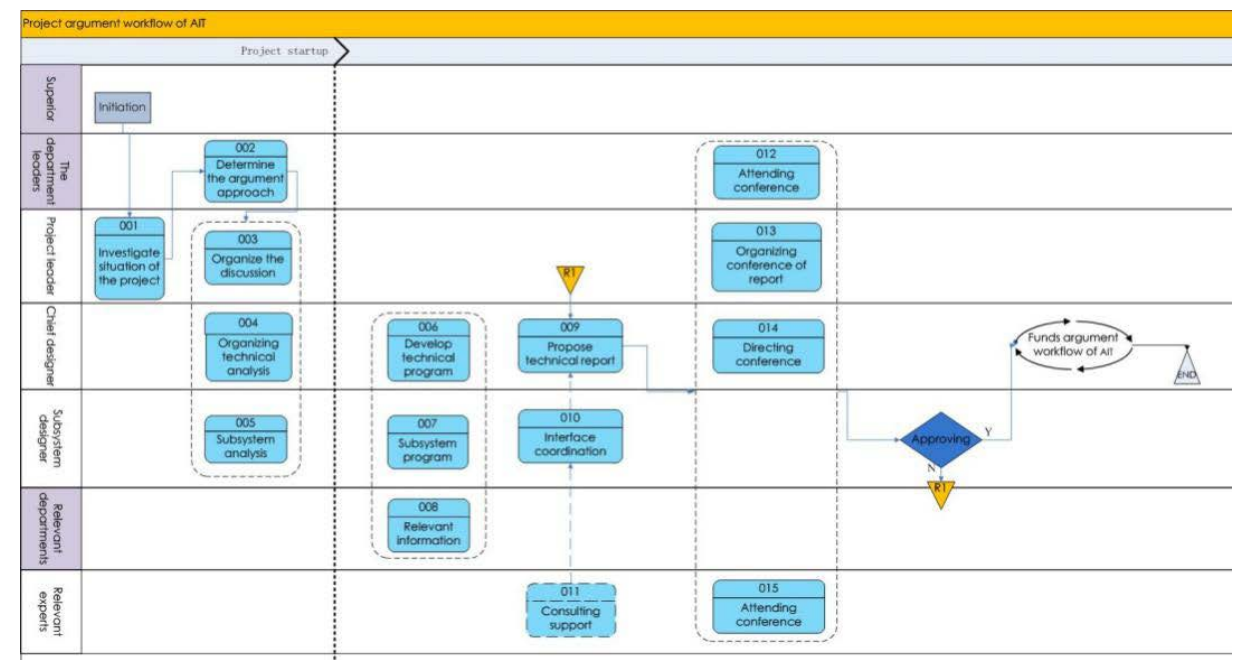

Figure. 1 Project argument workflow of AIT

\section{Risk Management}

Definition. Risk generally refers to a possible accident happening in the course of project enforcement. The accident may have the project unfinished under the prescribed cost and term and technological constraints or failed completely. The risk in all its definitions includes two features: one is uncertainty that means there is some probability of its happening; the other one is the fact that it would bring the undesired consequence or loss. The so-called risk management is the one that: (a) can identify potential problems and take measures to prevent their becoming actual problems and crises; (b) make an effort to guarantee the realization of project targets and to search for problems affecting quality consciously; (c) be aware of potential problems as soon as possible to make contribution to decisions making. (d) make every participants in the project aware of risks of their respective tasks and have them provide mechanisms and methods of problem solution.

Risk Management Methods. NASA treats risk management as an consecutive process that goes throughout all development phases and deals with all the products (hardware, software, systems and so on.), which is just the consecutive risk management method. It provides a good environment to make preventive decisions so as to incessantly estimate where things may went wrong (risk), determine the foremost risks, implement strategies dealing with these risks and ensure and measure their effectiveness. So the risk management is a part of the whole management and requires a continuous recognition and management of risks throughout all the phases of the project within its lifetime. The consecutive risk management within the lifetime of a project, there are six work items includes recognition, analysis, planning, tracking, control, information exchange and documents preparation. NASA has the quantitative analysis as another risk management method, namely $5 * 5$ 
risk matrix showed in the following Figure.2. Risk level is measured by the probability of risk happening and the consequences thereof. Both the mentioned probability and the seriousness may be represented by grade values. The probability level can be measured by the possibility of a risk changing into a real corresponding accident. The more higher the probability, the more possible the accident happens. The magnitude of consequences can be measured by the loss amount or the estimated harmful consequences, and the appraised objects suffering from the loss include achievements of project, realization of targets, progression of project, effects of fund, equipment and so on. The mark can be given to represent the consequence magnitude comprehensively caused by the risk.

\begin{tabular}{|c|c|c|c|c|c|c|}
\hline \multicolumn{7}{|c|}{ Risk Matrix } \\
\hline \multirow{6}{*}{ 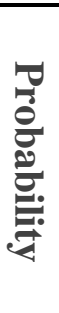 } & $\overline{E-5}$ & 10 & 16 & 20 & 23 & 25 \\
\hline & D-4 & 7 & 13 & 18 & 22 & 24 \\
\hline & $\mathrm{C}-3$ & 4 & 9 & 15 & 19 & 21 \\
\hline & B-2 & 2 & 6 & 11 & 14 & 17 \\
\hline & A-1 & 1 & 3 & 5 & 8 & 12 \\
\hline & & A-1 & B-2 & $\mathrm{C}-3$ & D-4 & $E-5$ \\
\hline & & & iit & f & equ & \\
\hline
\end{tabular}

Figure. 2 Risk management matrix

\section{Analysis of the Risk Management of the Spacecraft AIT Project}

From above, the project argument seems just the work that needs to be done before implementing the project. However, for the particularity of space mission, the spacecraft development project argument is in fact a task extending itself throughout the whole implementation of the project, which shall be the result on modifying some necessary nodes. The spacecraft development is also contained in the argument of spacecraft. The development plan has many uncertain factors which are easy to technologically accumulate at the spacecraft AIT which is a key and final procedure in the spacecraft development, and as a result bring higher risk to the spacecraft AIT project argument and decide whether the whole project can succeed smoothly or not. This paper analyzes the risk management of the spacecraft AIT project by the combination of the consecutive management method and risk matrix management method.

Risk Recognition. It verifies what risks are in the AIT project argument and make consideration before they raise negative result. It is a key step for spacecraft AIT project argument, because only the recognition of risks can eliminate or limit them. Risks recognized in this step mainly are of technology and fund. In aspect of technology, depending on features of spacecraft development, it determines whether AIT project teased through technological argument and analysis can realize AIT development objective, whether all kinds of the designed AIT development technologies, simulation verification experiments and equipment can be approved by experts, and the risks as result of uncertainty of its tip-level project argument, on technological implementation of the ATI through the new-platform or new-model development project.

Risk analysis. It mainly serves to transform the risk data to information related to decisions making, and determine the risk scope and relationships between risks by analysis. This paper takes the work item risk of the above AIT argument as an example to analyze. The develop unit would fail to fully clarify the work items of AIT development in the technological argument of the early project because of the complexity of the spacecraft development. The probability of this risk associates with development project and to the new model development is 5. The consequences of the risk: 1) in terms of technology, the consequences can be remedied by perfecting, amending and enforcing the work items after technological research and analysis and the magnitude of consequences is 2; 2) in terms of finance, the new added work item(s) may lack or need to apply for fund in its/their 
implementation, and the magnitude of consequences is 4 . So the comprehensive magnitude is 3 . Thus, this risk can be rated as 15 , which is a higher one.

Risk plan formulation. On the basis of fully recognizing the existing risks, a risk plan shall be made to decide how to deal with these risks and determine the means and strategies to alleviate the consequences resulting from the risk. From the above analysis, it can find that, to eliminate or alleviate the loss caused by the risk, the staffs responsible for the argument shall thoroughly research and analyze such top-level input as the targets, design plan of the project, communicate with the overall designers about technological issues in a iterative manner, have experts review the argument and then get the final argument report completed, thus to ensure the completion of the work items a greatest extent to alleviate the damage caused by the risk and lower the risk level. For the time being, this risk plan has obtained its place in the proceedings of the spacecraft AIT project argument.

Risk Tracking. During the course of the spacecraft AIT development, as the project went farther, related risk information shall be more promptly and exactly collected, processed and sent to the related staff and departments. The responsible staff for the argument shall determine whether the work items recognized in the precedent argument satisfy the requirements of the development, whether new work items are needed, which new items to add and the required fund scale. So, the responsible staff of the development shall track the project implementation, timely acquire risk information and give feedback.

Risk Control. This procedure includes reporting and analyzing the information and status acquired in the risk tracking procedure, deciding how to act and then implementing the decided actions. In this stage, the decisions maker of the spacecraft AIT project shall make judgment whether there is a change to the risk nature and the effectiveness of the precedent risk alleviation plan according to the data from the last stage. If no big change takes place, the risk control can be enforced by interior coordination to ensure the smooth completion of the AIT development, with the risks being controlled. If there are quite big adjustments to the development project, quite many development projects to be added or quite a large amount of fund to be demanded, then the new risk control measures shall be carefully found. For example, the risk consequences can be controlled by supplementing the newly added development projects as well as their fund, or submitting the ultra-estimate requirement to the project principle.

\section{Conclusion}

The spacecraft development is of high risk, which also determines many uncertainties and increases risks of its argument. In this paper, based on the risk management theory of NASA, the methods of argument and risk management that are fit for our country and have been put into use in the specified model development are proposed here. Spacecraft development is a process involving many and complex fields, so its risk management is corresponding difficult. This paper analyzes the risk management only in light of AIT, and to lay a solid base for the completion of the whole spacecraft development process, more wide risk studies of the spacecraft development are needed.

\section{References}

[1] K.Munir, L.Wiley: Exploring Risk Management for a Space Simulator, AIAA SPACE Conference \& Exposition (2009)

[2] Jin Xushu: Chinese Space Science and Technology Vol. 6 (2002), p. 26-32

[3] L.Chen: The study of Multi-model task management conflicts, Systems Engineering and Project Management Conference, AMM (2011).

[4] L.M. Zhang, X.M. Zhang: Introduction For Risk Management Analysis and examples of NASA (Aerospace Industry Management Press, China, 2012).

[5] Q.Ma, Y.C.Bian: Spacecraft Environment Engineering Press Vol. 5 (2010), p. 659-662 
[6] T. Bruce, Barkley: Project Risk Management (McGrawHill Professional, US, 2004).

[7] K.Tom: Identifying and Managing Project Risk: Essential Tools for Failure-Proofing Your Project (AMACOM, US, 2009). 